
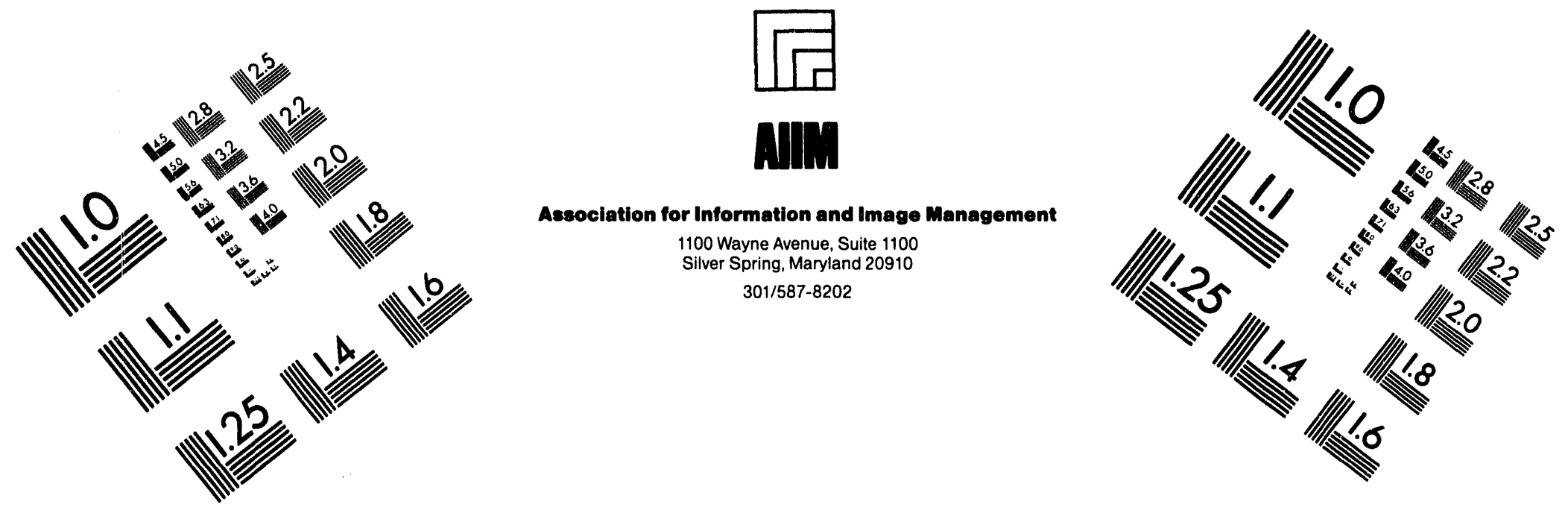

\title{
Centimeter
}

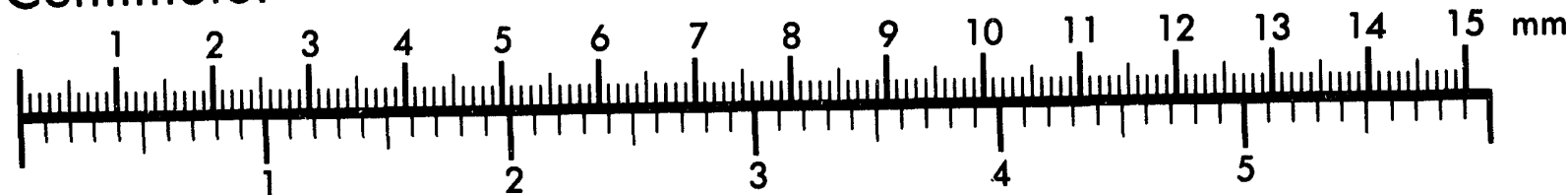

Inches
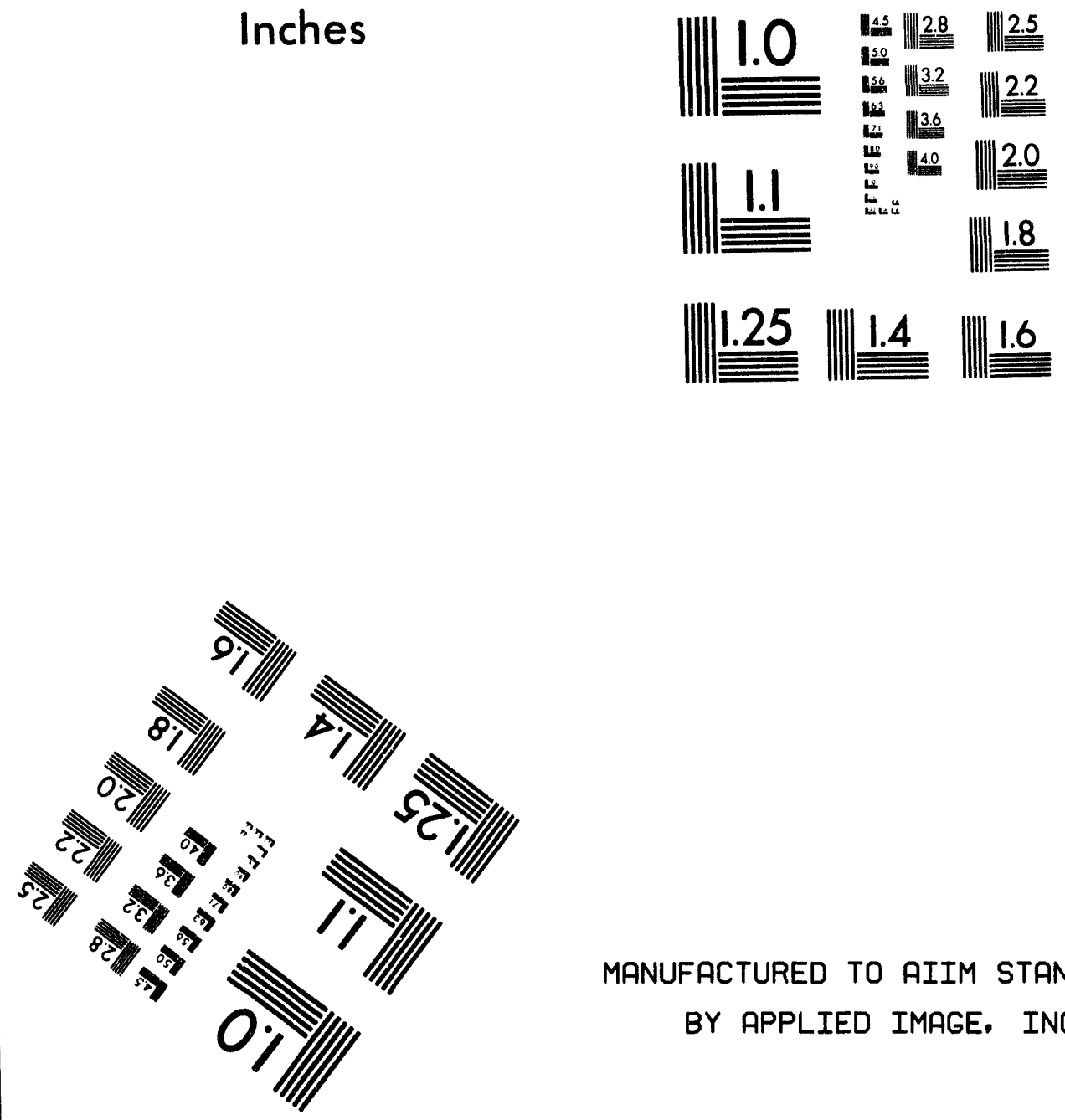

MANUFACTURED TO AIIM STANDARDS

BY APPLIED IMAGE, INC.

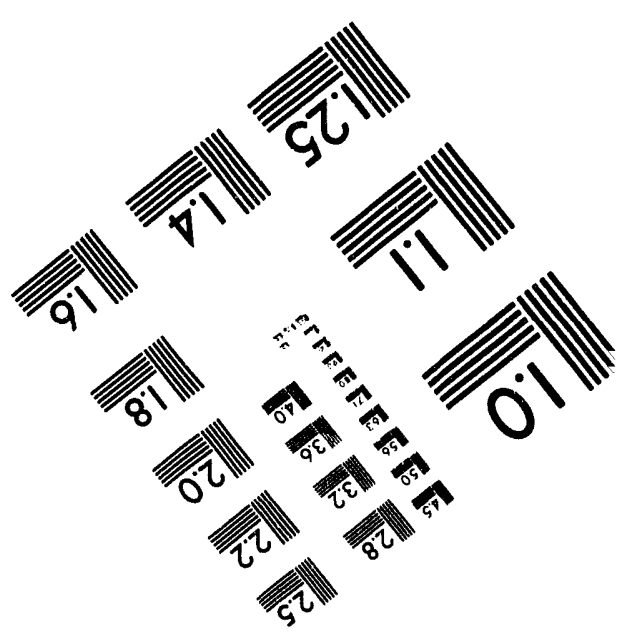



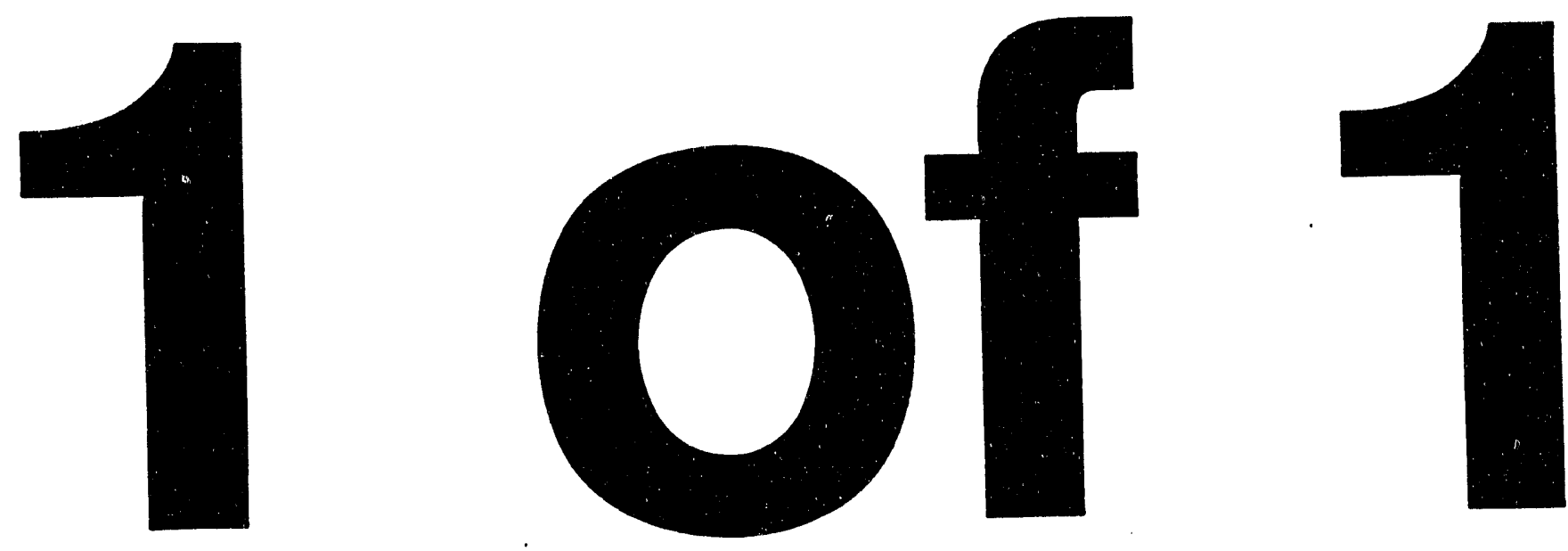


\title{
ELM-Related Fluctuations in PBX-M H-Modes
}

S.M. Kaye, T.S. Hahm, S. Sesnic, W. Tang, P. Roney, and W. Davis (PPPL, Princeton University, P.O. Box 451, Princeton N.J. 08543, U.S.A.), J. L. Dunlap and J. H. Harris (ORNL, Oak Ridge, Tn., 37831 U.S.A.)

\begin{abstract}
Edge Localized Modes, or ELMs, are at the same time both disadvantageous and advantageous features of $\mathrm{H}$-modes. ELMs can cause energy and particle losses from the plasma, with instantaneous energy losses reaching $40 \%$ of the total stored energy in the case of largeamplitude ELMs. The energy loss from these ELMs, or closely spaced smaller ELMs, may result in what is known as a beta-collapse, an event in which energy is lost over a substantial duration of the discharge. On the other hand, if controlled, the ELM related energy and, especially, impurity losses can lead to near steady-state discharge conditions with relatively low radiative power losses. The importance of ELMs in the development of the H-phase has led to numerous studies which attempt to uncover their nature. The purpose of the present work is to present additional observations of, most notably, high frequency magnetic fluctuations associated with ELMs. There are some observations here that are consistent with previously reported ones, namely the appearance of high frequency $(\geq 250 \mathrm{kHz})$ activity prior to the $\mathrm{D}_{\alpha}$ increase, suggesting again that the rise in $\mathrm{D}_{\alpha}$ is some delayed response to an instability occurring farther inside the plasma edge. While this high frequency activity is global, with high coherence for all coil pairs both on the inside and outside midplane, there is no identifiable mode structure. Reported here for the first time are observations of a very intense outward ballooning feature that appears simultaneously with the $\mathrm{D}_{\alpha}$ increase and lasts for about $5 \mathrm{msec}$. The toroidal mode structure of this feature is clearly identifiable, consisting of a series of toroidal harmonics from $n=3$ to 8 , at frequencies given by $f_{n}=f_{0}+n \Delta f$, with $f_{0}=30$ to $50 \mathrm{kHz}$ and $\Delta f=20$ to $30 \mathrm{kHz}$.
\end{abstract}




\section{ELM-Related Fluctuations in PBX-M H-Modes}

S.M. Kaye, T.S. Hahm, S. Sesnic, W. Tang, P. Roney, and W. Davis (PPPL, Princeton University, P.O. Box 451, Princeton N.J. 08543, U.S.A.), J. L. Dunlap and J. H. Harris (ORNL, Oak Ridge, Tn., 37831 U.S.A.)

\section{Introduction}

Edge Localized Modes, or ELMs, are at the same time both disadvantageous and advantageous features of $\mathrm{H}$-modes. ELMs can cause energy and particle losses from the plasma, with instantaneous energy losses reaching $40 \%$ of the total stored energy in the case of largeamplitude ELMs. The energy loss from these ELMs, or closely spaced smaller ELMs, may result in what is known as a beta-collapse, an event in which energy is lost over a substantial duration of the discharge [1]. On the other hand, ELMs can play a positive role. If controlled, the ELM related energy and, especially, impurity losses can lead to near steady-state discharge conditions with relatively low radiative power losses [2-4]. The compromise in this latter scenario is a reduction in the energy confinement time over that in the transient ELM-free discharges, but this reduction can be small, $\sim 20 \%$ [5].

The importance of ELMs in the development of the H-phase has led to numerous studies which attempt to uncover their nature. These studies have focused on understanding the fluctuations associated with the ELMs, as well as determining numerically the plasma stability to identify the most likely cause of these events. The results of these studies indicate the complexity of ELMs. For one thing, among the various studies there appears to be no consistent features of the associated fluctuations. Fluctuations occurring prior to the increase in the $\mathrm{D}_{\alpha}$ emission can be coherent [6,7] or incoherent [8]. The coherent fluctuations occurring prior to the $\mathrm{D}_{\alpha}$ increase are believed to have high poloidal mode numbers, $m=5$ to $15[6,9]$. The mode believed to be responsible for ELMs is somewhat uncertain, with studies implicating ideal ballooning [10], ideal external kinks [8], and ideal kinks leading to resistive ballooning [6]. A common thread among all these studies, however, is the nature of the free energy source for the modes, this being the total pressure. However, these instabilities do not account for all the observed ELMs (e.g., Type III on DIII-D).

The purpose of the present work is to present additional observations of, most notably, high frequency magnetic fluctuations associated with ELMs. The results underscore again that the increase in the $D_{\alpha}$ signal may merely be a delayed result of an instability that occurs farther inside the plasma. The results, in addition, indicate that while ballooning modes may be important, the ballooning appears to result from, and not cause, the ELM in the cases studied.

\section{Experimental Description}

The previous study of ELMs on PBX-M [8] was limited by the spatial and temporal coverage of the Mirnov coil diagnostics. At that time, the toroidal array of Mirnovs consisted of only six coils on the outside midplane, and one coil on the inside. This prevented a more complete description of the toroidal mode characteristics of the reported high frequency "precursors". In addition, the limitations of the data acquisition system meant that only $16 \mathrm{msec}$ of high sampling rate data $(1 \mathrm{MHz})$ could be recorded per discharge. Over the last two operating periods of PBX-M, however, the Mirnov coil array was upgraded so that there are ten coils on the outside midplane, and five coils on the inside. At the time the data to be presented here were taken, data from eight coils (six outside, two inside) were digitized by LeCroy 6810 digitizers at $1 \mathrm{MHz}$, with enough memory to record $\sim 130 \mathrm{msec}$ of data per discharge. This acquisition setup has facilitated greatly this ELM study, as the "capture" of ELMs was now less by chance.

An overview of a typical discharge used in this study is shown in Fig. 1. In this discharge, the plasma current was increased to $280 \mathrm{kA}$ by the start of $2.2 \mathrm{MW}$ of $\mathrm{D}^{\circ}$ neutral beam injection (NBI) into $\mathrm{D}^{+}$plasmas, and then held constant during the NBI for $200 \mathrm{msec}$. At 550 msec, the plasma current was ramped down at a rate of $1 \mathrm{MA} / \mathrm{sec}$. The plasma transitioned into the $\mathrm{H}$-mode at $450 \mathrm{msec}$, as evidenced by the drop in the $\mathrm{D}_{\alpha}$ emission and the increase in the rate of 


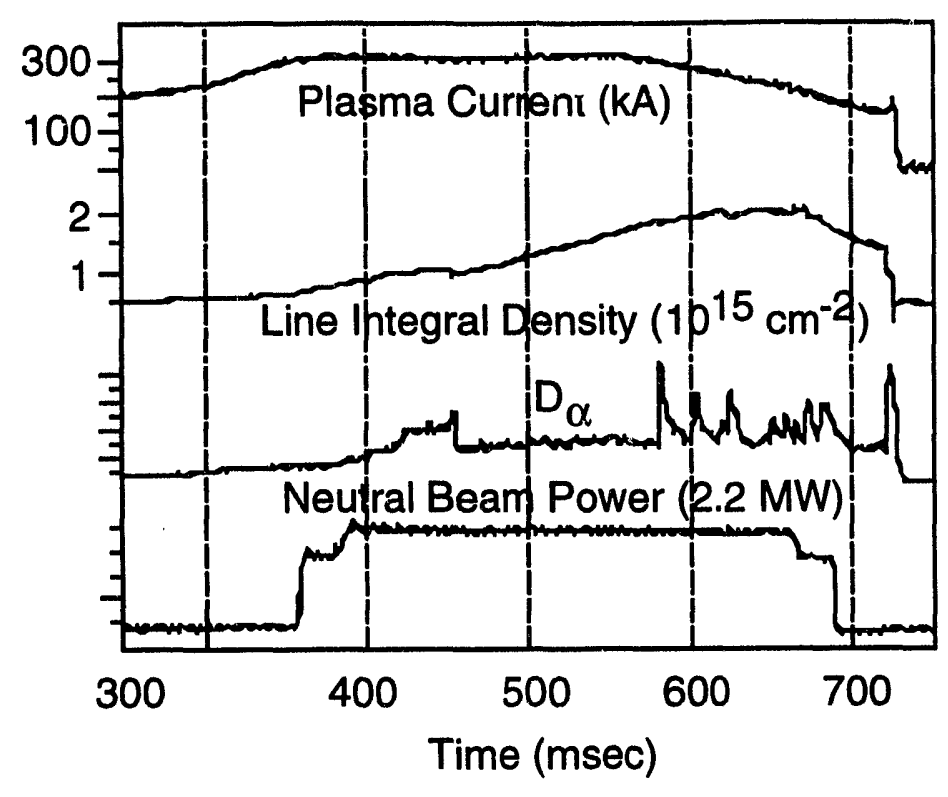

rise of the plasma density. An ELMfree phase lasted for about $130 \mathrm{msec}$. Large ELMs began at $580 \mathrm{msec}$, just after the plasma current began to ramp down. The correlation between the onset of ELMs and the current ramp down is not clear; large ELMs appeared in companion discharges with no current ramp down at approximately the same time. The discharge shown in Fig. 1 was below the Troyon beta limit at the start of the ELMs; just prior to the onset of ELMs, $\beta_{\text {pol }}=1.0$, $\beta_{\text {tor }}=0.7 \%$, and $\beta_{\text {tor }} /(\mathrm{I} / \mathrm{aB})=1$. This is in contrast to the previous PBX-M study [8] where the ELMs were a $\beta$ limit phenomenon, with $\beta_{\text {pol }} \geq 2.4$ and $\beta_{\text {tor }} /(\mathrm{I} / \mathrm{aB})=4.5$.

Fig. 1 Overview of an $\mathrm{H}$-mode discharge

\section{ELM-Associated Fluctuations}

In the remainder of the paper, three common spectral analysis quantities will be used. They are the cross-power, cross-coherence, and cross-phase as determined from the signals of pairs of Mirnov coils. The cross-power and coherence indicate which frequency components are most important, and from the cross-phase, which is calculated for different combinations of coil pairs with different toroidal separations, the toroidal mode structure of the oscillations can be deterrnined.

A color contour plot of the cross-coherence between two coils situated on the outer midplane and separated toroidally by $41^{\circ}$ is shown in Fig. 2 . Below the contour plot are time series traces of one of the Mirnov signals and the $\mathrm{D}_{\alpha}$ emission. The coherence, as shown in the plot, is calculated in time bins of $2 \mathrm{msec}$, averaging seven overlapping FFTs within that $2 \mathrm{msec}$ bin (without averaging, a cross-coherence identically equal to 1 would result). The contour plot highlights cross-coherence values in excess of 0.7 .

At the start of the data acquisition $(520 \mathrm{msec})$, the discharge had been in an ELM-free phase for over $70 \mathrm{msec}$ (ref. Fig. 1). The first large ELM appeared as an increase in the $\mathrm{D}_{\alpha}$ emission at $580 \mathrm{msec}$. The cross-coherence plot reveals several features of note. First of all, there was a $\sim 20 \mathrm{kHz}$ oscillation that lasted throughout the H-phase. This oscillation, which had a toroidal mode number of $\mathrm{n}=1$ and rotated in the co-NBI (and current) direction, appeared to be unaffected by the presence of the ELMs. A slightly higher frequency mode, $40-80 \mathrm{kHz}$, appeared approximately $30 \mathrm{msec}$ prior to the increase in $\mathrm{D}_{\alpha}$, then disappeared at the time of the $\mathrm{D}_{\alpha}$ rise, appearing again during the "quiet" time between the ELMs. This mode, which rotated in the counter-NBI (current) direction, consisted of a series of toroidal harmonics with n-values up to 7 . However, the cross-correlation between coil pairs was high $(>0.7)$ only for toroidal separations $<$ $90^{\circ}$.

A coherent feature appeared at high frequencies $(\geq 250 \mathrm{kHz})$ approximately $20 \mathrm{msec}$ before the $D_{\alpha}$ increase; the coherence in this frequency range was just above the threshold coherence value of 0.7 , until 3 to $4 \mathrm{msec}$ prior to the $D_{\alpha}$ increase when the coherence value increased to the 0.8 to 0.9 level. As abrupt as the increase in the $D_{\alpha}$ emission was the cessation of this high frequency coherence and the start of very intense, coherent activity near $200 \mathrm{kHz}$. This pattern of $\geq 250 \mathrm{kHz}$ activity appearing before, and a $200 \mathrm{kHz}$ burst appearing after the $D_{\alpha}$ increase was a 

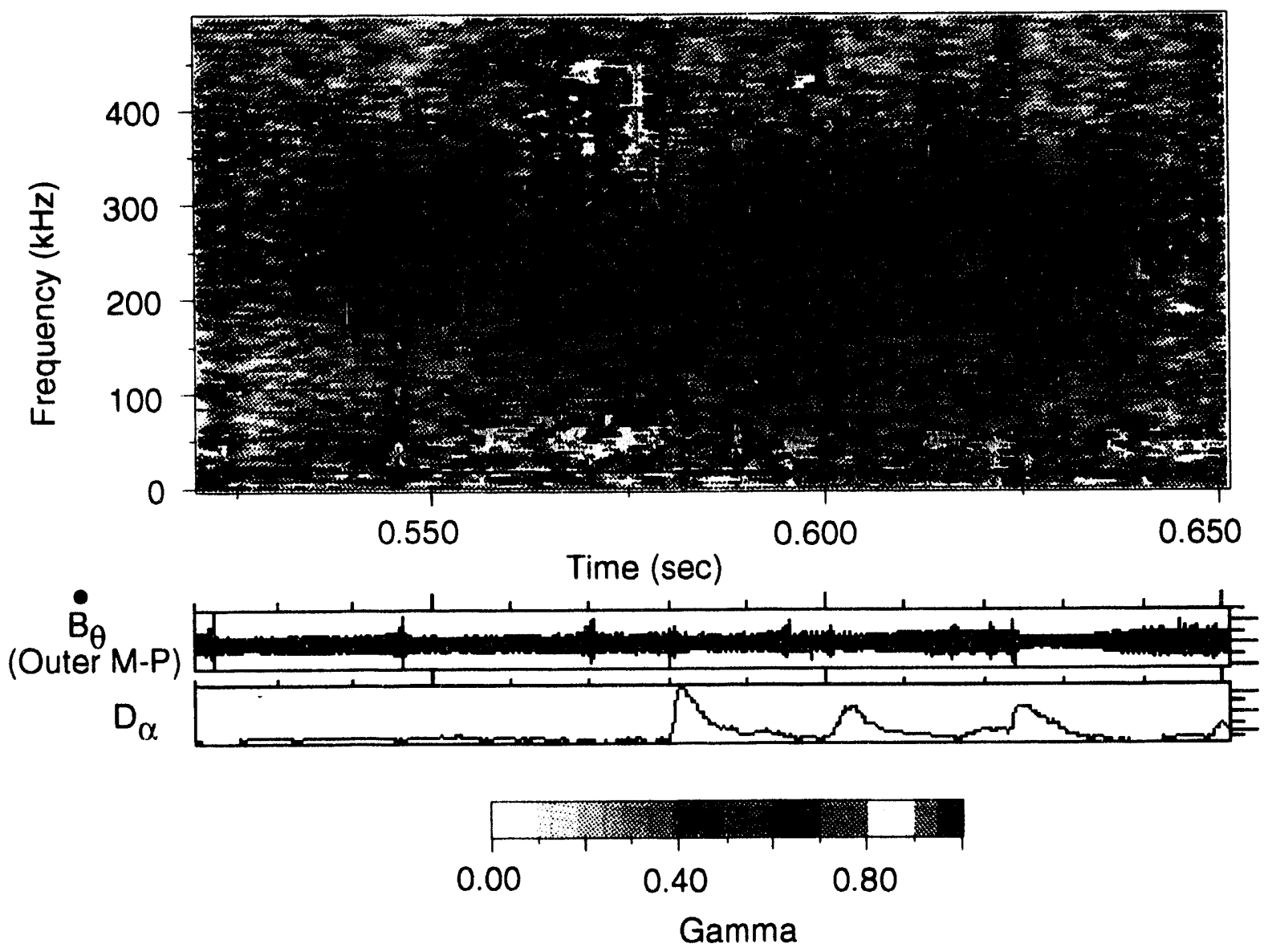

Fig. 2 Cross-coherence of a pair of outer midplane Mirnov coils separated toroidally by $41^{\circ}$

recurring feature in this discharge, as can be seen in subsequent ELMs in the figure, as well as in the rest of the discharges used for this study. The characteristics of the $200 \mathrm{kHz}$ feature were the same from burst-to-burst. As will also be discussed, the $\geq 250 \mathrm{kHz}$ coherence was high both on the inside and outside at all toroidal locations. However, the $200 \mathrm{kHz}$ activity exhibited a clear outward ballooning character, and was composed of a series of harmonics with toroidal mode numbers from $n=3$ to 8 . For the ensuing analyses, only data from the first ELM in each discharge will be examined; this will make the analysis of both the pre- and post- $\mathrm{D}_{\alpha}$ increase fluctuations "cleaner".

The cross-coherence shown in Fig. 2 was determined by calculating the Fourier spectrum of the data in 2 msec intervals. Consequently, what is shown in the figure is a relatively coarse overview of the development of the fluctuation activity during the discharge. To examine in more detail the evolution of the activity in the various frequency ranges, and especially to determine the precise timing of these activities with the increase in the $D_{\alpha}$ emission, the unfiltered and filtered time series data, along with the $\mathrm{D}_{\alpha}$ trace, are plotted in Fig. 3. The figure shows the measured $\partial B_{\theta} \partial t$ (top panel), the measured signal digitally filtered in the time domain for three different frequency ranges, $150-225 \mathrm{kHz}, 225-300 \mathrm{kHz}$, and $300-350 \mathrm{kHz}$, and the $D_{\alpha}$ trace. The data are plotted for a $40 \mathrm{msec}$ interval of time that includes an ELM, as indicated by the increase in the $D_{\alpha}$ emission at $596 \mathrm{msec}$.

The raw signal shown in Fig. 3 exhibited what appears to be the signature of a sawtooth crash at $591 \mathrm{msec}$, followed by an interval of spiky activity. At the time of the increase in $D_{\alpha}$, 


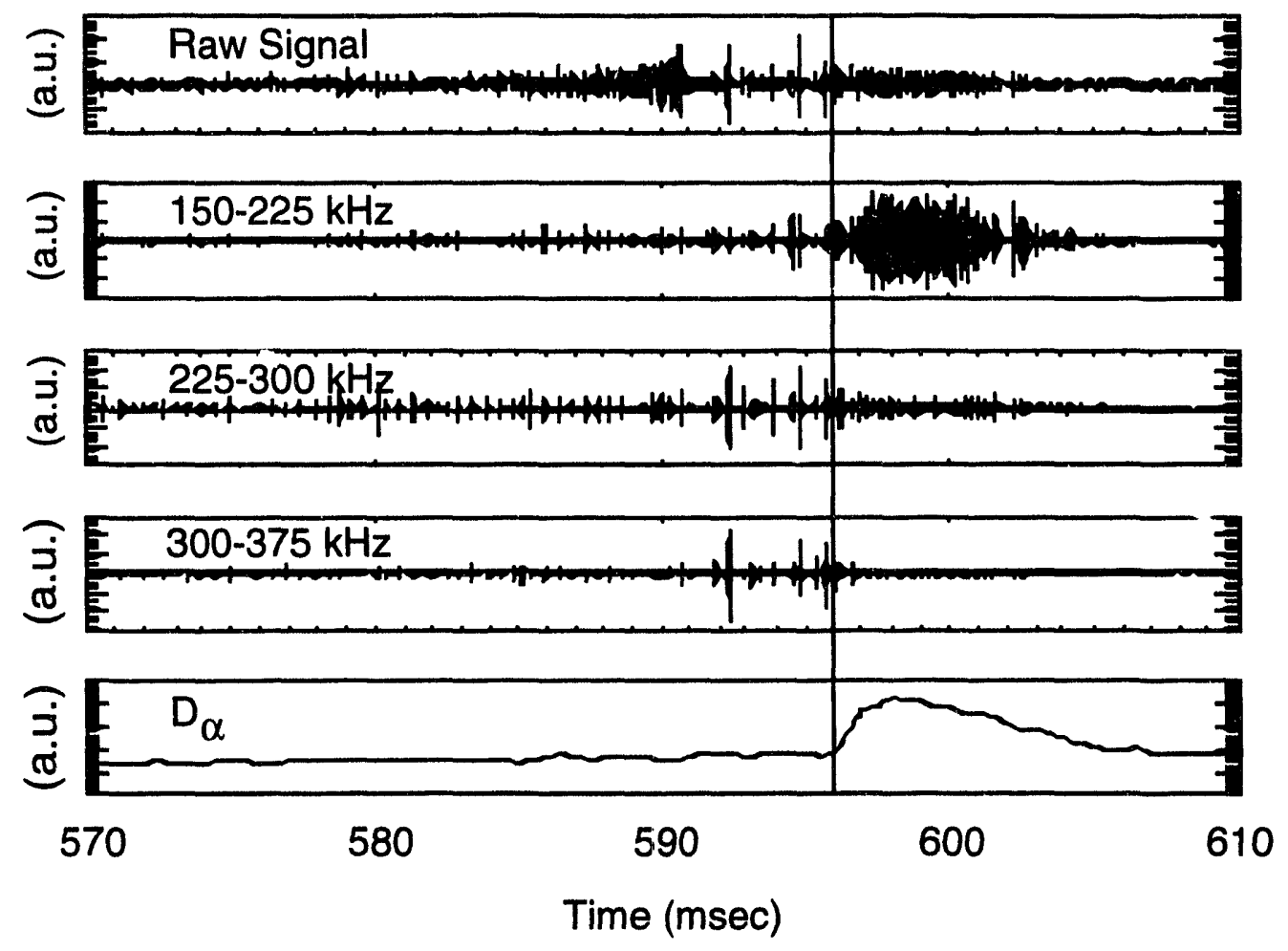

Fig. 3 Unfiltered (top) and filtered (middle) magnetic signals from an outside midplane Mirnov coil, and $\mathrm{D}_{\alpha}$ emission (bottom)

this spiky activity was suppressed and was replaced by lower amplitude continuous activity. The filtered signal in the $150-225 \mathrm{kHz}$ range exhibited a small increase in activity leading up to the time of the $\mathrm{D}_{\alpha}$ rise, as reflected by the slight increase in the amplitude of the bursty activity leading up to the rise. The biggest change in this frequency range was clearly the burst of continuous activity that was observed to grow at the time of the $\mathrm{D}_{\alpha}$ increase. This activity grew over a $1 \mathrm{msec}$ time scale, and lasted for approximately $5 \mathrm{msec}$. To within the temporal resolution of these diagnostics $(100 \mu \mathrm{sec})$, this comparison indicates that the increase in the continuous activity in this frequency range and the rise in the $\mathrm{D}_{\alpha}$ emission occurred simultaneously.

The activity seen in the filtered data in the two higher frequency ranges appeared to change very little until approximately $4 \mathrm{msec}$ prior to the increase in the $\mathrm{D}_{\alpha}$ emission. At that time, the activity was seen to increase in the form of short (fractions of a msec) bursts, separated from each other by 0.5 to $1.0 \mathrm{msec}$. In this example, there were about five of these bursts prior to the $D_{\alpha}$ increase. The increased amplitude of these bursts relative to the background level of activity was most pionounced in the highest frequency signal. Coincident with the $D_{\alpha}$ increase was a subsidence of these bursts, and the development of more continuous activity, similar to that seen in the lower frequency signal. At these higher frequencies, however, this continuous activity was much lower amplitude than that at lower frequency, and was clearly not as dominant a component as the activity before the $D_{\alpha}$ increase.

Detailed information about the mode structure can be obtained by comparing the crosspower and coherence of coils at various toroidal and poloidal separations. A comparison of the cross-spectral amplitude and coherence for two pairs of coils, each separated toroidally by $70^{\circ}$ with one pair on the outer midplane and one pair on the inner midplane, is shown in Figs. 4a and b. In Fig. $4 a$, the spectral characteristics were determined over a time period prior to the increase in $\mathrm{D}_{\alpha}$, from 575 to $579.5 \mathrm{msec}$ (the increase in $\mathrm{D}_{\alpha}$ occurred at $580 \mathrm{msec}$ ). Both the inside and the outside coils exhibit a broad peak in spectral amplitude for frequencies $\geq 250 \mathrm{kHz}$. Distinct peaks in the 
cross-coherence of both pairs of coils are seen near 230,280,350, and $440 \mathrm{kHz}$. Because only two inside midplane coils were connected to the fast acquisition system, toroidal mode information could be determined only for the outside coil set, where the toroidal separations ranged from $17^{\circ}$ to $181^{\circ}$. For this pre- $\mathrm{D}_{\alpha}$ rise phase of the ELM, there is no unambiguous identification of mode numbers associated with the various coherence peaks seen in Fig. 4a. This phase analysis indicates that the coherence peaks are associated with low- $n$ toroidal mode numbers ( $n=0$ to 2 ). However,
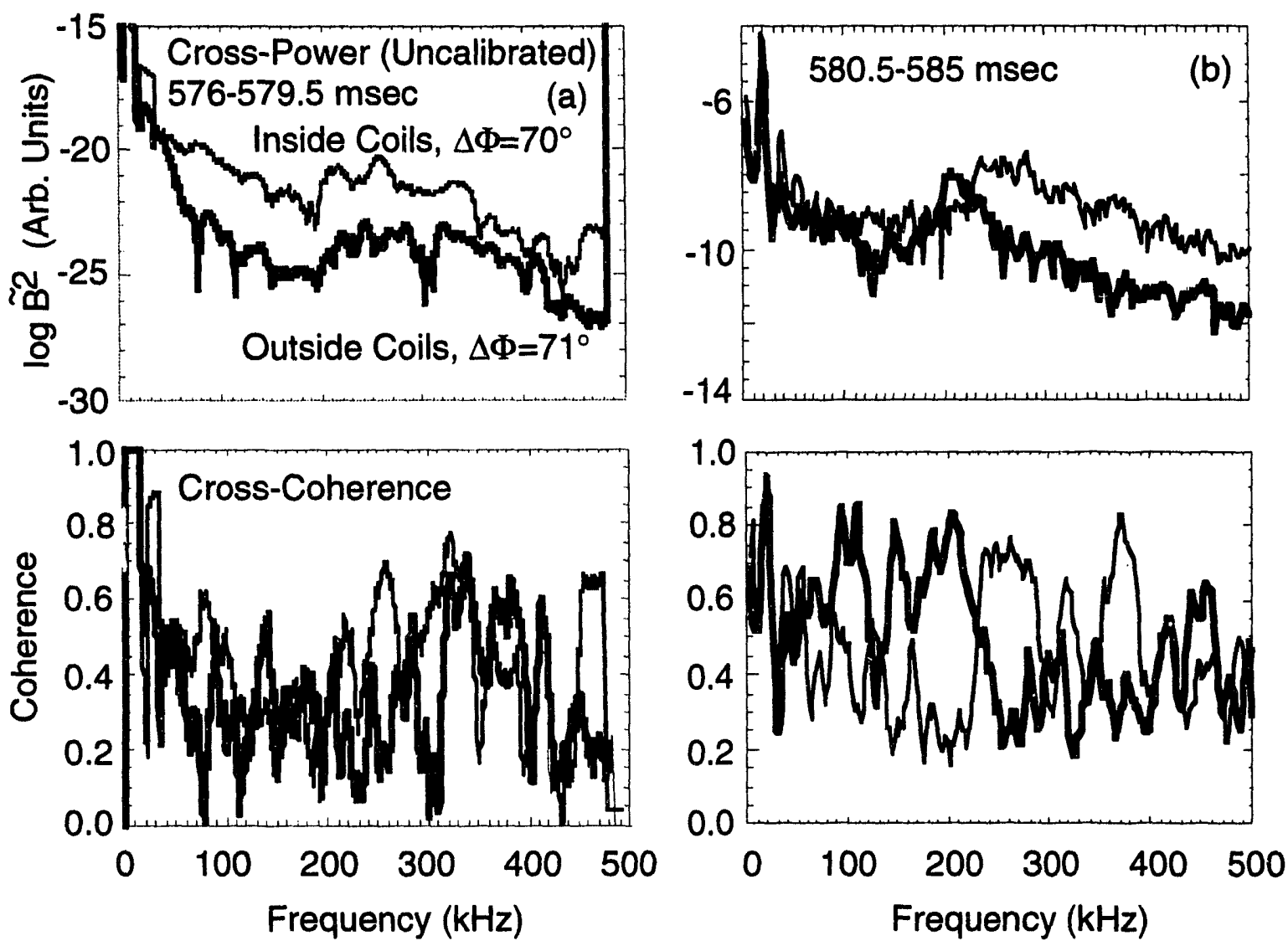

Fig. 4. Cross-power and coherence for Mirnov coil pairs before (a) and after (b) the rise in $D_{\alpha}$.

the peaks have little relation to each other; some rotate in the co-NBI, $\mathrm{I}_{\mathrm{p}}$ direction while others rotate in the opposite direction. In addition, the peaks are not harmonics of each other.

Nevertheless, the increased power and coherence during this phase is seen in coil pairs at all toroidal separations for $\mathrm{f} \geq 250 \mathrm{kHz}$, indicating the global nature of this activity.

A comparison similar to that made in Fig. $4 \mathrm{a}$ is shown in Fig. $4 \mathrm{~b}$ for the time period after the $\mathrm{D}_{\alpha}$ increase $(580.5-585 \mathrm{msec})$. In this plot, distinct differences between the inside and the outside coil pairs can be discerned. A peak in the perturbed field power and coherence is seen in the frequency range from 150 to $\sim 250 \mathrm{kHz}$. Lower power and coherence is seen at higher frequencies. The activity in the 150 to $250 \mathrm{kHz}$ range is actually composed of a series of peaks in coherence. Phase analysis of these peaks indicate a harmonic structure, with toroidal mode numbers increasing from $n=3$ near $150 \mathrm{kHz}$ to $n=8$ near $250 \mathrm{kHz}$. The modes rotate in the counterNBI (current) direction. The lower-n components $(n<4)$ exhibited high cross-coherence only for the smallest coil separations. The observed harmonic structure can be described by the relation $\mathrm{f}_{\mathrm{n}}=\mathrm{f}_{0}+\mathrm{n} \Delta \mathrm{f}$, where $\Delta \mathrm{f}=20-30 \mathrm{kHz}$ and $\mathrm{f}_{0}=30-50 \mathrm{kHz}$. The peak in spectral power and coherence 
for frequencies $\leq 250 \mathrm{kHz}$ is seen for all outside coil pairs. This indicates that the mode, while localized to the outside poloidally, has a large toroidal extent.

The inside coil pair shown in Fig. 4b exhibits no amplitude or coherence peaks for $f \leq 230$ $\mathrm{kHz}$, indicating a strong outward ballooning character of the $200 \mathrm{kHz}$ feature. Instead, the inside coils exhibit a broad peak in amplitude and coherence for frequencies $\geq 250 \mathrm{kHz}$, similar to the spectra seen in the pre- $D_{\alpha}$ rise period in Fig. 4a. Also similar to these spectra, little change in phase is seen across this frequency range, implying no harmonic structure. Little else can be said concerning the toroidal mode structure of the inside oscillations from only the one coil pair. Low coherence is seen in the outer coils at these higher frequencies.

\section{Conclusions}

The results of this study underscore the complexity of the ELM phenomena. There are some observations here that are consistent with previously reported ones, namely the appearance of high frequency activity prior to the $\mathrm{D}_{\alpha}$ increase, suggesting again that the rise in $\mathrm{D}_{\alpha}$ is some delayed response to an instability occurring farther inside the plasma edge. While this high frequency activity is global, with high cross-coherence for all coil pairs both inside and outsicie, there is no identifiable mode structure. Not observed before is the very intense outward ballooning feature that appears simultaneously with the $D_{\alpha}$ increase and lasts for about $5 \mathrm{msec}$. The toroidal mode structure of this feature is clearly identifiable, consisting of a series of toroidal harmonics from $n=3$ to 8 , at frequencies given by $f_{n}=f_{0}+n \Delta f$.

One candidate for explaining the frequency dependence discussed above is the beam-driven kinetic ballooning mode. This mode can be destabilized below the ideal limit via resonance with energetic particles [11,12]. In an extension of [12], the observed frequency may be written as $\omega_{o b}=\omega_{c h}+\vec{k} \bullet \vec{v}_{E}$, where $\omega_{c h}$ is a characteristic, $\mathrm{n}$-independent frequency given by $\omega_{b m}$ or $\omega_{t m}^{o b}$, the bounce of transit frequency of beam ions at the maximum beam injection energy. $\vec{v}{ }_{F}$ is the plasma rotation velocity due to $\vec{E} \times \vec{B}$ motion. In our case, the plasma rotation is predominantly poloidal and is due to the radial electric field [13]. The $\vec{k} \bullet \bar{v}_{E}$ term gives the n-dependence. In most of the cases studied, the $f_{0}=2 \pi \omega_{c h}$ term is consistent with the ion bounce frequency. The incremental frequency, $\Delta \mathrm{f}=20-30 \mathrm{kHz}$, is consistent with the presence of a poloidal rotation, v $\theta=2 \pi f_{\theta} a=2 \pi(\Delta f) a / q \cong 1 \times 10^{6} \mathrm{~cm} / \mathrm{sec}$ in the electron diamagnetic drift direction, matching the poloidal rotation velocity measured by the UCLA fast reciprocating probe [13].

\section{Acknowledgments}

The authors wish to acknowledge discussions with J. Manickam and L. Schmitz. The work was supported by U.S. Department of Energy Contract No. DE-AC02-76-CHO3073 at PPPL and DE-AC05-84OR21400 at ORNL.

\section{References}

1] H. Kugel et al., in Controlled Fusion and Plasma Physics, Proc. of $14^{\text {th }}$ Eur. Conf., Madrid, Vol 11D, Part 1 (1987) 185.

2] F. Wagner et al. in Plasma Physics and Controlled Nuclear Fusion Research Vol I (1991) 473.

3] DIII-D Team in Ref. 2, Vol I, p. 69.

4] P.R. Thomas in Controlled Fusion and Plasma Physics, Proc. of $19^{\text {th }}$ Eur. Conf., Innsbruck, Vol. 16C (1992) 239.

5] D. Schissel et al. in Ref. 4, Vol. 16C, p. 235.

6] H. Zohm et al., N'sc. Fusion $\underline{32}$ (1992) 489.

7] R. Stambaugh et al., J'lasma Physics and Controlled Fusion $\underline{30}$ (1988) 1585.

8] S.M. Kaye et al., Nu.c. Fusion $\underline{30}$ (1990) 2621.

9] P. Cripwell et al., in Controlled Fusion and Plasma Physics, Proc. of $16^{\text {th }}$ Eur. Conf., Venice, Vol I (1989) 225. 
10] P. Gohil et al., Phys. Rev. Lett. $\underline{61}$ (1988) 1603.

11] H. Biglari and L. Chen, Phys. Rev. Lett. 67 (1991) 3681.

12] S.T. Tsai and L. Chen, Phys. Fluids B $\underline{5}$ (1993) 3284.

13] G. Tynan et al., this conference. 
Dr. F. Paoloni, Univ. of Wollongong, AUSTRALIA

Prof. M.H. Brennan, Univ. of Sydney, AUSTRALIA

Plasma Research Lab., Australian Nat. Univ., AUSTRALIA

Prof. I.R. Jones, Flinders Univ, AUSTPALIA

Prof. F. Cap, Inst. for Theoretical Physics, AUSTRIA

Prof. M. Heindler, Institut für Theoretische Physik, AUSTRIA

Prof. M. Goossens, Astronomisch Instituut, BELGIUM

Ecole Royale Militaire, Lab. de Phy. Plasmas, BELGIUM

Commission-European, DG. XII-Fusion Prog., BELGIUM

Prof. R. Bouciqué, Rijksuniversiteit Gent, BELGIUM

Dr. P.H. Sakanaka, Instituto Fisica, BRAZIL

Prof. Dr. I.C. Nascimento, Instituto Fisica, Sao Paulo, BRAZIL Instituto Nacional De Pesquisas Espaciais-INPE, BRAZIL

Documents Office, Atomic Energy of Canada Lid., CANADA

Ms. M. Morin, CCFMTokamak de Varennes, CANADA

Dr. M.P. Bachynski, MPB Technologies, Inc., CANADA

Dr. H.M. Skarsgard, Univ. of Saskatchewan, CANADA

Prof. J. Teichmann, Univ. of Montreal, CANADA

Prof. S.R. Sreenivasan, Univ. of Calgary, CANADA

Prof. T.W. Johnston, INRS-Energie, CANADA

Dr. R. Bolton, Centre canadien de fusion magnétique, CANADA

Dr. C.R. James, Univ. of Alberta, CANADA

Dr. P. Lukác, Komenského Universzita, CZECHO-SLOVAKIA

The Librarian, Culham Laboratory, ENGLAND

Library, R61, Rutherford Appleton Laboratory, ENGLAND

Mrs. S.A. Hutchinson, JET Library, ENGLAND

Dr. S.C. Shama, Univ. of South Pacific, FIJI ISLANDS

P. Mähönen, Univ. of Helsinki, FINLAND

Prof. M.N. Bussac, Ecole Polytechnique,, FRANCE

C. Mouttet, Lab. de Physique des Milieux lonisés, FRANCE

J. Radet, CEN/CADARACHE - Bat 506, FRANCE

Prof. E. Economou, Univ. of Crete, GREECE

Ms. C. Rinni, Univ. of loannina, GREECE

Preprint Library, Hungarian Academy of Sci., HUNGARY

Dr. B. DasGupta, Saha Inst. of Nuclear Physics, INDIA

Dr. P. Kaw, Inst. for Plasma Research, INDIA

Dr. P. Rosenau, Israel Inst. of Technology, ISRAEL

Librarian, International Center for Theo Physics, ITALY

Miss C. De Palo, Associazione EURATOM-ENEA , ITALY

Dr. G. Grosso, Istituto di Fisica del Plasma, ITALY

Prof. G. Rostangni, Istituto Gas Ionizzati Del Cnr, ITALY
Dr. H. Yamato, Toshiba Res \& Devel Center, JAPAN

Prof. I. Kawakami, Hiroshima Univ., JAPAN

Prof. K. Nishikawa, Hiroshima Univ., JAPAN

Librarian, Naka Fusion Research Establishment, JAERI, JAPAN

Director, Japan Atomic Energy Research Inst., JAPAN

Prof. S. Itoh, Kyushu Univ., JAPAN

Research Info. Ctr., National Instit. for Fusion Science, JAPAN

Prof. S. Tanaka, Kyoto Univ., JAPAN

Library, Kyoto Univ., JAPAN

Prof. N. Inove, Univ. of Tokyo, JAPAN

Secretary, Plasma Section, Electrotechnical Lab., JAPAN

S. Mori, Technical Advisor, JAERI, JAPAN

Dr. O. Mitarai, Kumamoto Inst. of Technology, JAPAN

Dr. G.S. Lee, Korea Basic Sci. Ctr., KOREA

J. Hyeon-Sook, Korea Atomic Energy Research Inst., KOREA

D.I. Choi, The Korea Adv. Inst. of Sci. \& Tech., KOREA

Prof. B.S. Liley, Univ. of Waikato, NEW ZEALAND

Inst of Physics. Chinese Acad Sci PEOPLE'S REP. OF CHINA

Library, Inst. of Plasma Physics, PEOPLE'S REP. OF CHINA

Tsinghua Univ. Library, PEOPLE'S REPUBLIC OF CHINA

Z. Li, S.W. Inst Physics, PEOPLE'S REPUBLIC OF CHINA

Prof. J.A.C. Cabral, Instituto Superior Tecnico, PORTUGAL

Prof. M.A. Hellberg, Univ. of Natal, S. AFRICA

Prof. D.E. Kim, Pohang Inst. of Sci. \& Tech., SO. KOREA

Prof. C.I.E.M.A.T, Fusion Division Library, SPAIN

Dr. L. Stenflo, Univ. of UMEA, SWEDEN

Library, Royal Inst. of Technology, SWEDEN

Prot. H. Withelmson, Chalmers Univ. of Tech., SWEDEN

Centre Phys. Des Plasmas, Ecole Polytech, SWITZERLAND

Bibliotheek, Inst. Voor Plasma-Fysica, THE NETHERLANDS

Asst. Prof. Dr. S. Cakir, Middle East Tech. Univ., TURKEY

Dr. V.A. Glukhikh,Sci. Res. Inst. Electrophys.I Apparatus, USSR

Dr. D.D. Ryutov, Siberian Branch of Academy of Sci., USSR

Dr. G.A. Eliseev, I.V. Kurchatov Inst., USSR

Librarian, The Ukr.SSR Academy of Sciences, USSR

Dr. L.M. Kovrizhnykh, Inst. of General Physics, USSR

Kernforschungsanlage $\mathrm{GmbH}$, Zentralbibliothek, W. GERMANY

Bibliothek, Inst. Für Plasmaforschung, W. GERMANY

Prof. K. Schindler, Ruhr-Universitát Bochum, W. GERMANY

Dr. F. Wagner, (ASDEX), Max-Planck-Institut, W. GERMANY

Librarian, Max-Planck-Institut, W. GERMANY 

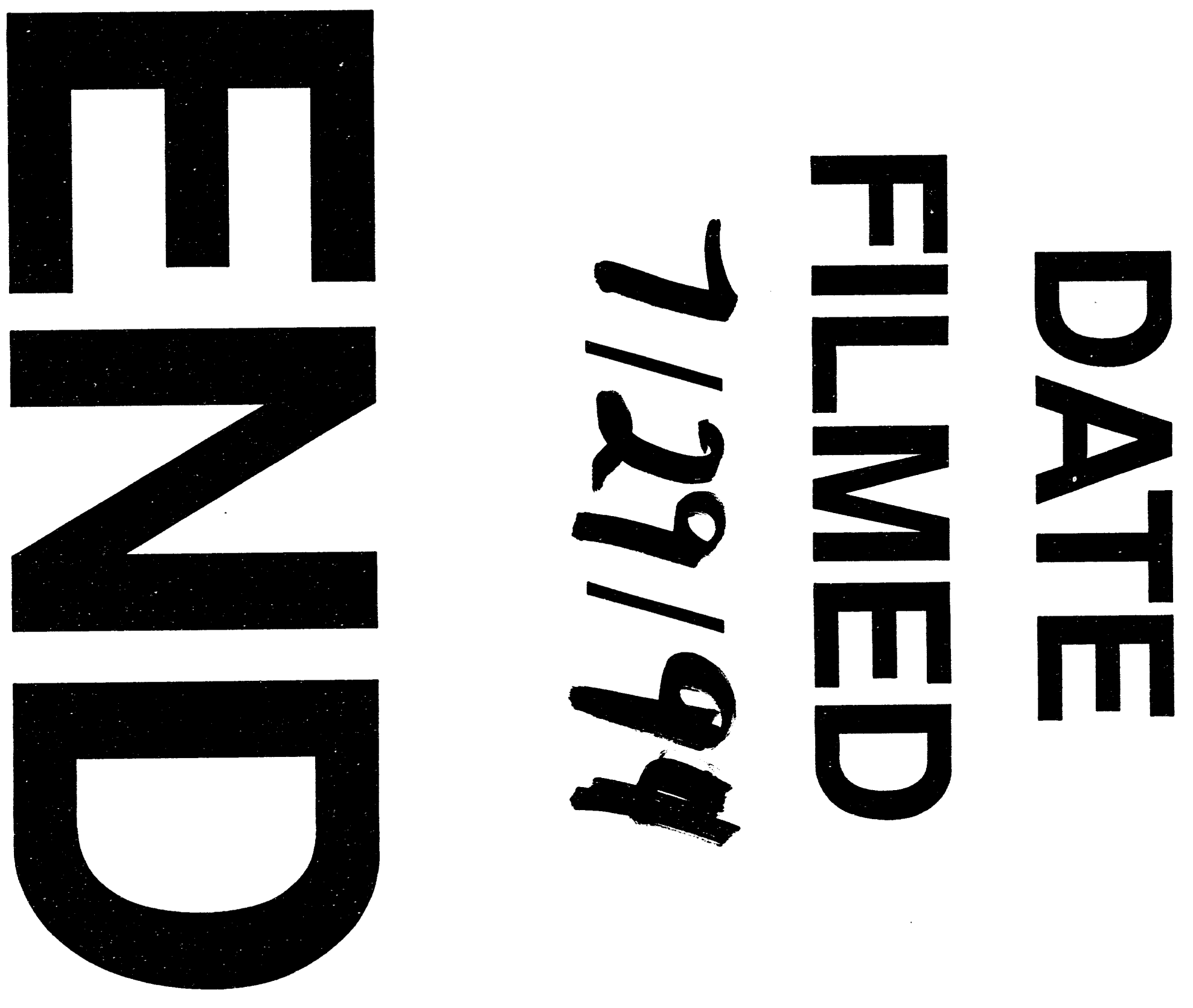


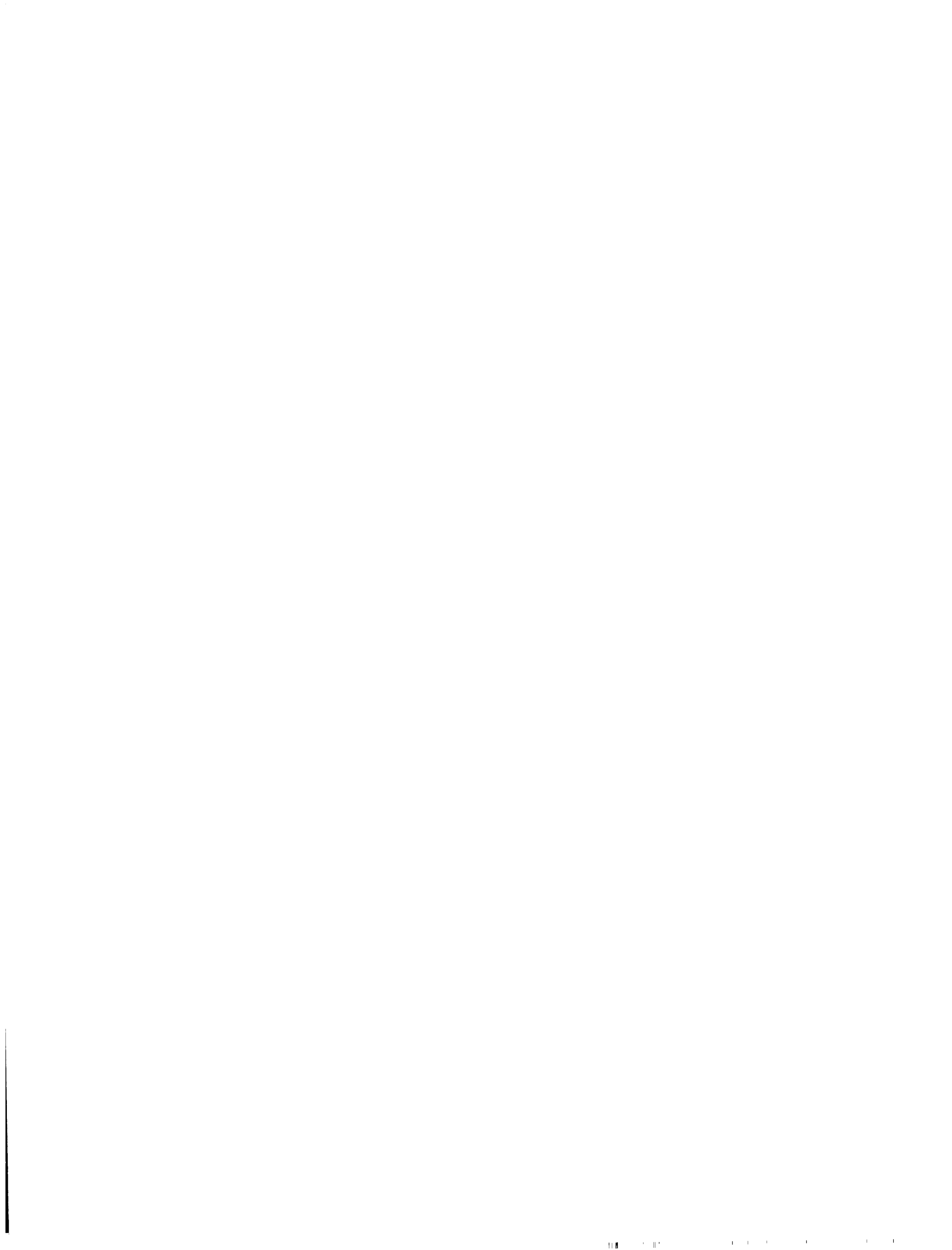

